http://dx.doi.org/10.6113/TKPE.2014.19.3.233

\title{
$\mathrm{DC}$ 배전용 3상 $\mathrm{AC} / \mathrm{DC} \mathrm{PWM}$ 컨버터의 새로운 3차방정식 Droop 제어를 적용한 병렬운전 기법 \\ 신수철 ${ }^{1}$, 이희 준 ${ }^{2}$, 박윤욱 $^{2}$, 홍석진 $^{2}$, 원 충연 $^{\dagger}$
}

\section{Parallel Operation Method using New Cubic Equation Droop Control of Three-Phase AC/DC PWM Converter for DC Distribution Systems}

\author{
Soo-Choel Shin ${ }^{1}$, Hee-Jun Lee ${ }^{2}$, Yun-Wook Park ${ }^{2}$, Seok-Jin Hong ${ }^{2}$, and Chung-Yuen Won ${ }^{\dagger}$
}

\begin{abstract}
This paper proposes that each converter supplies the power using the proposed droop control for the parallel operation of the converters. The proposed method is easy to increase the power as parallel system in $\mathrm{DC}$ distribution. By improving conventional droop-control method used in $\mathrm{AC}$ grid newly, a droop controller is designed to apply droop control in DC grid. And the control method of the proposed droop controller is explained particularly. In this paper, by applying the proposed control method to DC distribution system, propriety is verified through the simulation and the experiment.
\end{abstract}

Keywords: droop control, parallel operation, microgird, DC distribution system, AC/DC PWM converter

\section{1. 서 론}

최근 꾸준하게 증가하는 전자 부하와 더불어 직류배 전에 대한 장점으로 인하여 직류 배전시스템에 대한 관 심이 높아지고 있다. 상업용 빌딩에서 대부분의 부하는 $\mathrm{PC}$, 모니터, TV, 조명등 직류 부하들로 이루어져 있다. 직류 전력을 공급하기 위한 직류배전 시스템은 교류 배 전 시스템에 비하여 역율, 효율, 에너지관리 등에서 장 점을 갖으나 신뢰성, 시스템구성의 복잡성 측면에서 단 점을 갖는다. 특히 변압기를 포함하는 교류배전 시스템 은 시스템의 단일 용량을 쉽게 증가시킬 수 있는 장점 을 갖는 반면에 직류배전 시스템은 전력용 반도체의 용 량 제한으로 인하여, 시스템의 단일 용량을 증가시키기 어려운 단점을 갖는다. 이러한 이유로 직류배전 시스템 은 용량 증가를 위하여 병렬제어 운전이 필수적이다 ${ }^{[1,2]}$. 교류시스템의 병렬운전은 전압의 위상각, 회전방향, 전

Paper number: TKPE-2014-19-3-5

Print ISSN: 1229-2214 Online ISSN: 2288-6281

† Corresponding author: woncy@skku.edu, College of

Information and Communication Eng. Sungkyunkwan Univ.

Tel: +82-31-290-7115 Fax: +82-31-290-7179

${ }^{1}$ LG Electronics Co., Ltd

${ }^{2}$ College of Information and Communication Eng.

Sungkyunkwan University

Manuscript received Jan. 24, 2014; accepted Mar. 1, 2014

- 본 논문은 2013년 추계학술대회 우수추천논문임
압의 크기의 동기화 제어로 가능하며, 직류 시스템의 병 렬운전은 전압의 크기 동기화 제어로 가능하다. 전압형 컨버터를 갖는 직류배전 시스템은 DC-Link에 커패시터 를 사용하여, 직류전압의 임피던스가 작으므로 병렬 운 전시 작은 전압차이에 의하여 두 시스템 사이에 큰 돌 입전류를 발생시킬 수 있고 병렬 시스템 사이에 제어진 동을 발생시킬 수 있다. 또한 2 대 이상의 전력변환기에 서 센서의 오차, 선로 임피던스에 의해 병렬 시스템 간 순환전류가 발생하게 된다. 순환전류는 교류의 무효전력 과 유사하여 시스템의 전체손실과 직결된다 ${ }^{[3,4]}$. 이러한 이유로 직류배전시스템에서 병렬운전과 동시에 직류전 압 제어를 위하여 master 시스템과 slave 시스템으로 구 분하여, master 시스템은 직류전압제어를 수행하며, slave 시스템은 전력 또는 전류제어를 수행하여야 한다. 그러나 slave 시스템의 응답성 또는 용량이 master 시스 템보다 크면, master 시스템의 낮은 응답성 및 저용량으 로 인하여 부하 변동 시 직류전압의 변동이 필연적으로 수반된다. 전력변환기를 사용하는 시스템은 시스템의 용 량 증가시 전력용 반도체의 스위칭 주파수를 감소시킬 필요성이 있다. 그림 1 은 상업용 빌딩의 직류배전 시스 템의 구성이다. 일반적인 상업용 빌딩은 변압기들을 병 렬 연결하여 부하에 전력을 공급한다. 그러나 직류배전 을 위한 수백 $[k W]$ 이상의 용량을 갖는 $\mathrm{AC} / \mathrm{DC}$ 컨버터 는 시스템의 방열구조가 복잡하고 보호회로 및 시스템 구조 등이 복잡한 단점을 갖는다 ${ }^{[5]}$. 


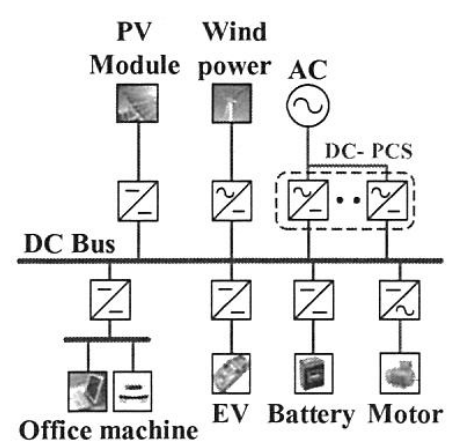

Fig. 1 Configuration of DC distribution systems in commercial building

이러한 단점을 해졀하고 직류배전 시스템을 구성하기 위하여 소용량 시스템을 다병렬 운전이 가능하도록 구 성할 필요가 있다 ${ }^{[6,7,8]}$. 제안한 논문은 동일용량의 직류 배전용 $\mathrm{AC} / \mathrm{DC}$ 컨버터의 병렬운전 방법을 제안한다. 제 안한 방식은 비선형 방정식을 이용하여 slave 시스템이 master 시스템의 출력전류와 동일한 출력을 발생시키도 록 제어를 추종한다. 제안한 제어기는 master 시스템과 slave 시스템이 부하를 동일하게 분담하며, 동일 용량의 두 시스템의 병렬운전 시에도 병렬시스템 사이에 제어 진동을 최소화하고 순환전류를 저감한다. 제안한 방법은 전력변환기의 병렬 운전에 용이하게 적용 할 수 있다.

\section{2. 직류배전 시스팀}

\section{1 직류비전 시스텀의 구성}

직류배전 시스템은 태양광 발전 및 신재생 에너지원 과 연계가 용이하기 때문에 양방향 전력제어가 가능 하 여야 한다. 또한 시스템의 효율 향상 및 유지보수성을 위하여 slave 시스템의 증설이 용이하여야한다. 그림 2 는 2 병렬회로를 갖는 직류배전 시스템이다. 직류배전 시 스템의 병렬운전을 위하여 slave 시스템의 직류전압은 master 시스템의 직류 전압과 동일하게 제어 한 후 두 시스템을 연계 하여야한다. 그러나 각각 다른 제어기를 갖는 두 시스템에서 $\mathrm{AD}$ 오차, 센서의 오차둥으로 인하 여 측정 전압과 실제전압은 차이가 있을 수 있다. 이러 한 상황에서 두 시스템을 연계하면 두 시스템 사이에 순환전류가 발생한다. 특히 대용량의 전력변환 회로는 회로의 임피던스가 낮기 때문에 낮은 전압차이에 의해 서도 큰 돌입전류와 순환 전류를 발생시킬 수 있다. 그 러므로 순환전류 저감을 위하여 병렬운전시 slave 시스 템은 전압제어 완료 후 master 시스템과 연계시점에서 전류제어 또는 전력제어로 전환하여 master 시스템과 연계할 필요성이 있다. 본 논문의 시률레이션과 실험에 적용한 전력변환기 각 모듈의 용량은 $50[\mathrm{~kW}]$ 이고, 입 력전압은 $380\left[V_{\mathrm{rms}}\right]$ 이며, 직류전압은 $700\left[V_{d c}\right]$ 이다.

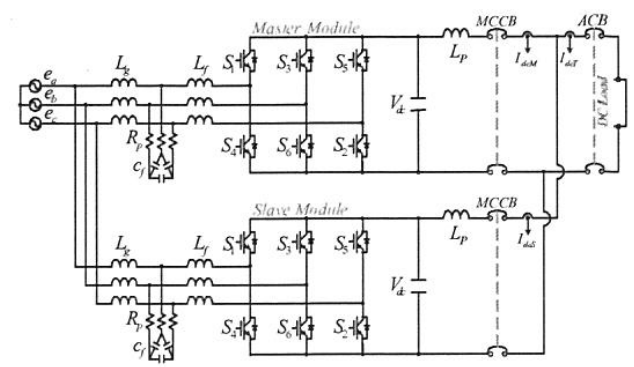

Fig. 2 DC distribution system having parallel circuit

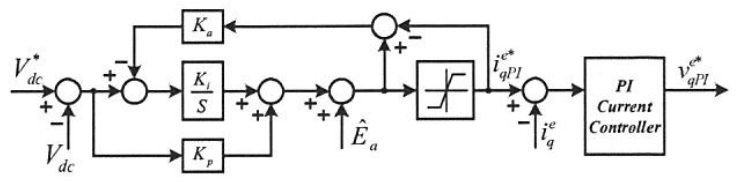

Fig. 3 PI voltage controller blocks having anti-windup

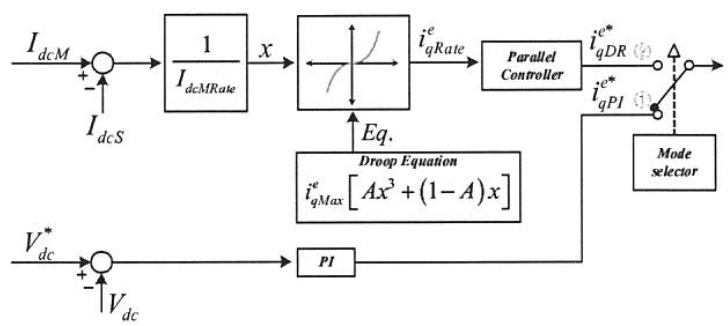

Fig. 4 The proposed Droop control blocks

\subsection{Master 모듈의 졔어}

그립 3은 안티와인드업을 갖는 PI 전압 제어기이다. 전류제어기도 전압제어기와 같은 구조를 갖는다. 본 논 문에서 master 시스템은 전압제어를 수행하여 직류배전 전압을 $700\left[V_{d c}\right]$ 로 유지한다.

\section{3. 제안하는 Droop 제어}

\subsection{Droop 졔어를 위한 Slave 모듈의 전류제어}

그림 4는 slave 시스템의 Droop 제어를 위한 블록도 이다. slave 시스템은 master 시스템과 같이 직류 $700\left[V_{d c}\right]$ 를 제어한 후 master 시스템과 연계시점에서 master 시스템의 부하전류와 동일한 전류를 출력할 수 있도록 전류 제어를 수행한다. 이때 master 시스템과 slave 시스템의 정격용량이 같으므로 slave 시스템의 전 류제어에 의하여 master 시스템에서 제어하는 직류전압 의 진동을 유발할 수 있다. 그러므로 slave 시스템의 제 어웅답은 master 시스템에 비하여 느리게 제어하거나 제어량을 축소할 펄요성이 있다. 그립 4는 master 시스 템과 slave 시스템의 전류 오차를 3차 방정식을 이용하 여 오차량을 변화 시킨다. 


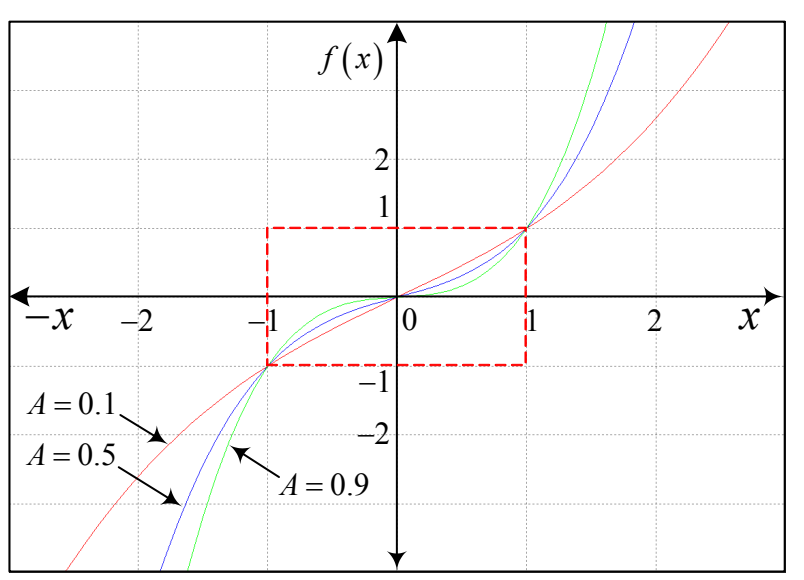

Fig. 5 The proposed cubic equation graph

\subsection{Droop 제어 방정식}

그림 5 는 식 (1)의 3 차 방정식의 그래프 이다. $A$ 는 계수로서 Droop 제어를 위하여 사용자가 임의로 설정할 수 있다. 식 (1)의 함수 $f(x)$ 는 오차 $x=1$ 인 점에서 항상 $f(x)=1$ 이 출력되는 3 차방정식이다. master 시스 템의 출력전류와 slave 시스템의 출력전류 차이에 대한 오차를 그림 5 와 같이 변화 시켜 오차 $x$ 가 선형으로 감 소할때 식 (1)을 이용하여 오차가 비선형으로 감소하도 록 변화시킨다. 계수 $\mathrm{A}$ 가 클수록 전류오차에 대하여 함 수 출력 값이 작다. 따라서 이를 이용하면 큰 전류차이 에서는 slave 시스템의 출력전류를 빠르게 상승시키고 작은 전류차이에서는 slave 시스템의 출력전류를 작게 상승시켜 병렬운전 최종점에서 slave 시스템에 의한 master 시스템의 전압 진동을 억제할 수 있다.

$$
f(x)=\left[A x^{3}+(1-A) x\right]
$$

\subsection{AC/DC PWM 컨버터의 $\mathrm{q}$ 축 지령 설계}

제안한 Droop 제어 방식은 master 시스템은 직류 전 압제어를 수행하고, slave 시스템은 직류전류 제어를 수 행한다. 직류전류를 제어하기 위하여 3상 $\mathrm{AC} / \mathrm{DC}$ 컨버 터의 $q$ 축 전류를 제어함으로써 직류 전류는 간접적으로 제어된다. slave 시스템의 제어전류양은 master 시스템 과의 출력전류 오차를 교류측의 $q$ 축 전류로 환산하여 병렬제어기의 피드백 값으로 받는다. 그 후 병렬제어기 에 의하여 직류출력전류의 오차는 0 으로 제어되므로 순 환전류를 억제하도록 3상 $\mathrm{AC} / \mathrm{DC}$ 컨버터의 3상전류를 제어한다. 식 (2)는 전력변환기의 손실이 없다고 가정한 상태에서 $\mathrm{AC} / \mathrm{DC}$ 컨버터의 $q$ 축전류와 직류전류 $I_{d c}$ 의 관계식이다. 여기서, $P_{A C}$ 은 $\mathrm{AC} / \mathrm{DC}$ 컨버터의 교류전력, $P_{D C}$ 는 직류전력, $I_{s}$ 는 $\mathrm{AC} / \mathrm{DC}$ 컨버터의 상전류, $i_{q}^{e}$ 는 동기좌표상에서 $\mathrm{AC} / \mathrm{DC}$ 컨버터의 유효축 전류, $i_{q M a x}^{e}$ 는 $\mathrm{AC} / \mathrm{DC}$ 컨버터의 정격용량에서의 $q$ 축 전류이다. 그리고 $V_{d c}=700\left[V_{d c}\right], V_{L L}=380\left[V_{\mathrm{rms}}\right], \cos \theta=1$ 이므로

$$
\left\{\begin{array}{l}
P_{A C}=\sqrt{3} V_{L L} I_{s} \cos \theta \\
P_{D C}=V_{d c} I_{d c} \\
P_{A C}=P_{D C} \\
\sqrt{3} V_{L L} I_{s} \cos \theta=V_{d c} I_{d c} \\
I_{s}=\frac{V_{d c} I_{d c}}{\sqrt{3} V_{L L} \cos \theta} \\
i_{q}^{e}=\frac{\sqrt{2}}{\sqrt{3}} \frac{V_{d c} I_{d c}}{V_{L L}} \\
i_{q M a x}^{e}=\frac{\sqrt{2}}{\sqrt{3}} \frac{P_{A C}}{V_{L L} \cos \theta}=107.434[A]
\end{array}\right.
$$

$$
\left\{\begin{array}{l}
x=\frac{1}{I_{d c M R a t e}}\left(I_{d c M}-I_{d c S}\right) \\
f(x)=i_{q M a x}^{e}\left[A x^{3}+(1-A) x\right]
\end{array}\right.
$$

$i_{q}^{e} \approx 1.5 I_{d c}$ 의 전류비를 갖는다.

식 (3)은 (1)을 이용하여 정격용량 $50[k W]$ 의 slave시 스템에 적용하기 위한 방정식이다. 시뮬레이션 모델은 각 모듈의 정격용량이 $50[k W]$ 이므로 $\mathrm{AC} / \mathrm{DC}$ 컨버터의 최대 $q$ 축전류 $i_{q M a x}^{e}$ 는 $107[A]$ 이다. master 시스템의 직류 출력전류와 slave 시스템의 직류 출력전류 사이에 발생하는 전류 오차를 이용하여 slave 시스템의 $q$ 축 전 류를 제어하기 위하여 식 (3)과 같이 방정식을 설계한다. 여기서, $I_{d c M}$ 은 master 모듈의 출력전류, $I_{d c S}$ 는 slave 모듈의 출력전류, $I_{d c M R a t e}$ 는 master 모듈의 정격 출력전 류, $i_{q M a x}^{e}$ 는 모듈의 최대 $q$ 축 전류, $A$ 는 그림 5 에서 보 인 전류오차의 그래프를 생성하기 위한 계수이다.

\subsection{AC/DC PWM 컨버터의 제어블록도}

그림 6 은 시뮬레이션에서 사용한 $\mathrm{AC} / \mathrm{DC}$ 컨버터의 제 어 알고리즘 블록이다. 입력전압은 $380 \pm 10[\%]$ 범위 내에서 정상 동작하도록 시스템을 설계하였다. 초기충전 회로는 커패시터 $C_{V S C}$ 가 방전되어 있을 때 커패시터로 입력되는 과전류를 방지하여 컨버터의 IGBT 와 병렬구 조로 결합되어 있는 Diode의 소손을 방지한다. 제어 블 록은 직류 전압제어기, 역률 제어기, 계통의 위상각을 계산하는 Phase Lock Loop 블록, 유·무효 전력을 계산 하는 유·무효 전력 계산기를 포함한다. 그리고 slave 시스템의 병렬연계 시 동작하는 전류 Droop 제어기를 포함하고 있다. 또한 계통전원의 고장발생 시에 교류 계 통 전압의 불 평형을 해석하기 위한 Positive Sequence 계산 블록을 포함하여, 역상분 전압의 크기를 계산하고 이를 이용하여 시스템을 보호할 수 있도록 설계하였다. 표 1 은 시뮬레이션과 실험에 적용한 시스템의 사양이다. 


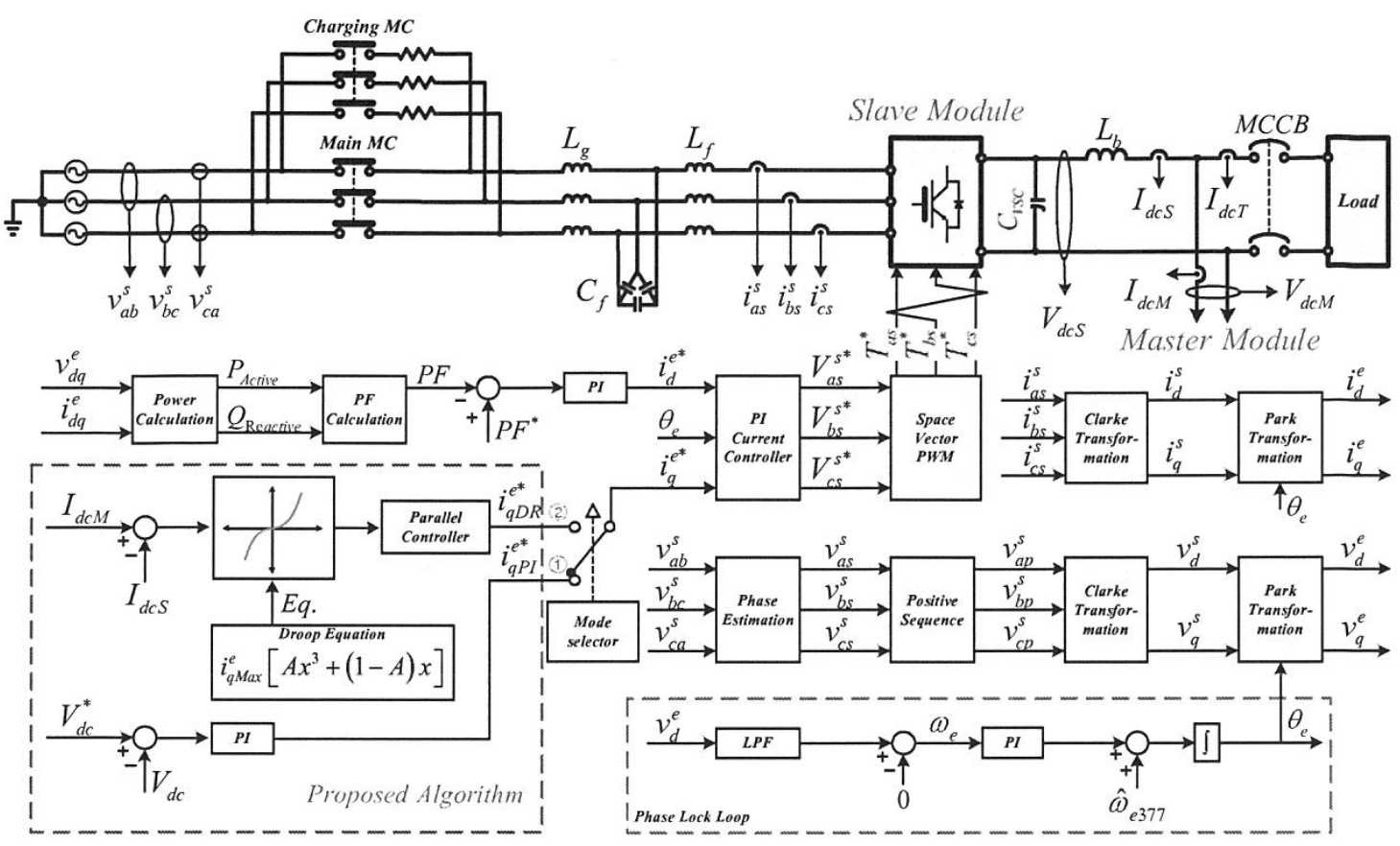

Fig. 6 Control blocks of DC distribution system

Table 1 System parameters

\begin{tabular}{ccc}
\hline Symbol & Quantity & Value \\
\hline$P$ & Power & $50[\mathrm{~kW}]$ \\
\hline$E$ & Grid voltage & $380\left[\mathrm{~V}_{\mathrm{s}}\right]$ \\
\hline$I_{s}$ & Grid current & $76\left[\mathrm{~A}_{\mathrm{s}}\right]$ \\
\hline$f_{g}$ & Grid frequency & $60[\mathrm{~Hz}]$ \\
\hline$f_{s}$ & $\begin{array}{c}\text { Switching } \\
\text { frequency }\end{array}$ & $5[\mathrm{kHz}]$ \\
\hline$L_{g}$ & $\begin{array}{c}\text { Line filter } \\
\text { inductance }\end{array}$ & $120[\mu \mathrm{H}]$ \\
\hline$L_{f}$ & $\begin{array}{c}\text { Boost } \\
\text { inductance }\end{array}$ & $500[\mu \mathrm{H}]$ \\
\hline$C_{f}$ & $\begin{array}{c}\text { Line filter } \\
\text { capacitance }\end{array}$ & $50[\mu \mathrm{F}]$ \\
\hline$C_{V S C}$ & $\begin{array}{c}\text { DC-link } \\
\text { capacitance }\end{array}$ & $10200[\mu \mathrm{F}]$ \\
\hline$L_{b}$ & $\begin{array}{c}\text { DC-line filter } \\
\text { inductance }\end{array}$ & $500[\mu \mathrm{H}]$ \\
\hline \multicolumn{3}{c}{}
\end{tabular}

\section{4. 시뮬래이션}

그립 7은 이론적 분석을 검중하기 위하여 시률레이션 을 퉁하여 Droop 제어를 확인하였다. 시률레이션은 PSIM 소프트웨어를 이용하였으며, 제어 알고리즘은 그 림 6의 제어블럭을 Visual C++을 이용하여 DLL파일을 생성하여 수행하였다.

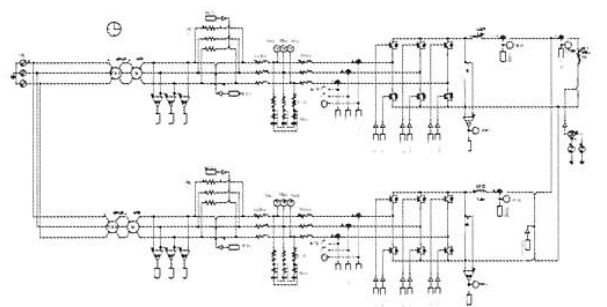

Fig. 7 Simulation schematic

그림 8은 제안한 알고리즘을 이용하여 master 시스템 과 slave 시스템을 병렬 연결한 후 저항 부하를 투입, 해제 하였을 경우에 $\mathrm{DC}$ bus의 직류전압, $\mathrm{AC} / \mathrm{DC} \mathrm{PWM}$ 컨버터의 $q$ 축 전류, $\mathrm{DC}$ 부하전류를 나타낸 것이다. 0 0.1 초 사이 초기 충전회로를 통하여 초기 충전 동작을 수행한다. 0.1초 이후 $\mathrm{AC} / \mathrm{DC} \mathrm{PWM}$ 컨버터는 스위칭을 시작하며 $\mathrm{DC}$-link를 $700[\mathrm{~V}]$ 로 전압 제어한다. 0.5초에 두 개의 컨버터 모듈은 병렬MC가 닫히고 병렬운전을 시작한다. 무부하 시 병렬 제어가 된 상태에서 0.75 초에 $50[\mathrm{~kW}]$ 부하가 스탭으로 컨버터와 연계되고 1.25 초에 해제된다. 이때 제안한 Droop 곡선을 따라 출력전류 오 차가 제어되고 서로 다른 웅답성을 갖으며 부하에 전류 를 공급한다. $q$ 축 전류를 퉁하여 master 모듈과 slave 모듈의 전류응답특성이 다른 것을 확인 할 수 있다. 또 한 출력전류의 오차가 병렬제어기에 의하여 제어되므로 동일한 전류량으로 부하를 분담하는 것을 확인 할 수 있다. 


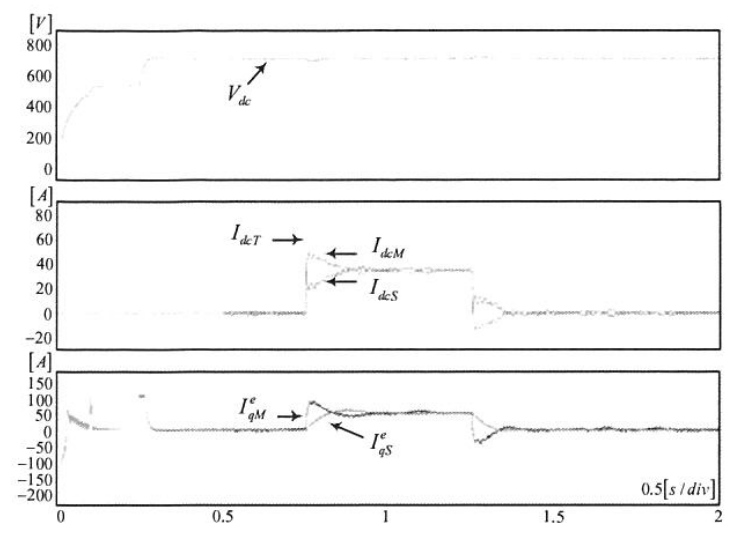

Fig. 8 DC current sharing waveform in parallel operation

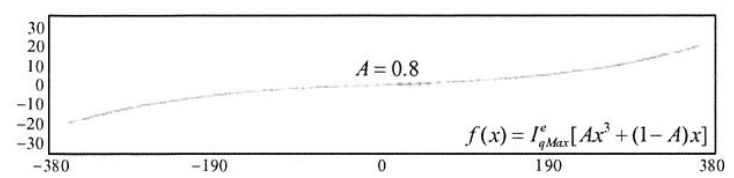

Fig. 9 Q-axis current reference of slave system following load current

slave 시스템의 제어웅답이 master 시스템과 비교하여 더욱 빠르거나, 동일할 때 두 시스템사이에 전압진동이 발생할 수 있다. 제안한 제어기는 두 시스템 사이의 제 어진동을 최소화 시키면서 적절하게 부하전류를 분담한 다. 그립 9에서 가로축은 master 모듈과 slave모듈의 전 류오차이고 그에 따른 제안한 Droop 곡선을 따라 계산 된 출력전류 파형을 보인다. 제안한 방정식의 그래프와 동일하게 전류제어 됨을 확인할 수 있다. 병렬 제어 시 각 컨버터의 Droop 곡선 방정식 식 (1)의 $A$ 값을 0 1 까지 적절하게 조절하여 설계하면, 대용량 시스템에서 직류 전압제어 시 전압의 진동 폭을 저감할 수 있다.

\section{5. 실 험}

제안한 방법을 이용하여 3상 $\mathrm{AC} / \mathrm{DC} \mathrm{PWM}$ 컨버터의 직류 출력전압 $700[V]$ 에서 병렬 운전을 수행 하였다. 그립 10은 제안한 Droop 제어 방법을 적용 하였을 때 직류전압, 부하전류, 각 컨버터의 출력 전류를 보여준 다. 그림과 같이 직류 $700[\mathrm{~V}]$ 에서 두 컨버터의 병렬 운 전이 원활히 수행됨을 확인 하였으며, $24[\mathrm{~kW}]$ 부하 투 입시 적절하게 부하 전류를 분담함을 확인 하였다. 직류 배전 시스템의 병렬 운전 시 $\mathrm{DC}$ bus의 전압제어는 master 컨버터 1 대가 담당하고 나머지 컨버터는 Droop 제어를 수행한다. 그러나 Droop 제어를 수행하는 컨버 터는 상황에 따라 다른 Droop 곡선을 이용하여 제어할 필요가 있다. 그 이유는 직류전압을 제어하는 master 컨 버터의 제어 웅답성을 확보하기 위합이다.

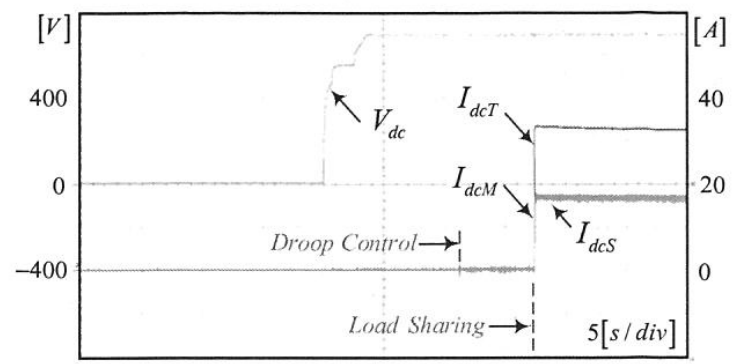

Fig. 10 Parallel operation using the proposed droop control

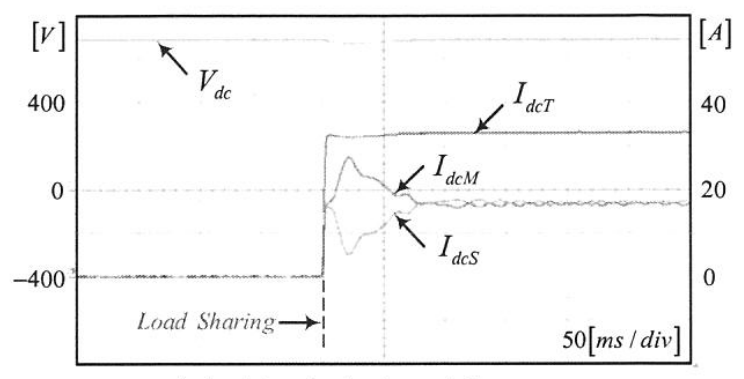

(a) $f(x)=\left[A x^{3}+(1-A) x\right], A=0.2$

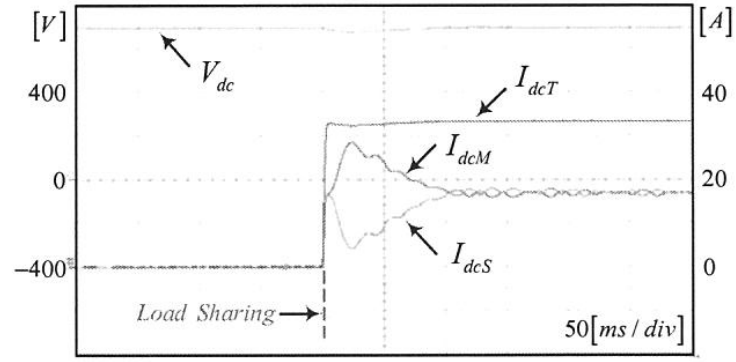

(b) $f(x)=\left[A x^{3}+(1-A) x\right], A=0.5$

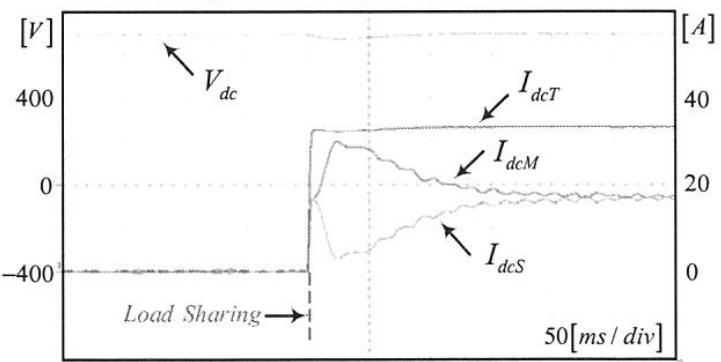

(c) $f(x)=\left[A x^{3}+(1-A) x\right], A=0.8$

Fig. 11 Load current, DC voltage and output current waveform of each converter according to the change of $\mathrm{A}$ in Droop control

그립 11 은 식 (1)의 $A$ 계수를 $0.2 \rightarrow 0.5 \rightarrow 0.8$ 로 변 경 하고 Droop 제어를 수행하였을 경우에 부하전류, 각 컨버터의 출력전류 및 직류제어 전압파형을 보여준다. 그립과 같이 부하가 Step으로 연결 되었을 때 Droop 제 어를 통하여 부드럽게 제어전압인 $700[V]$ 로 제어됨을 확인 하였다. 


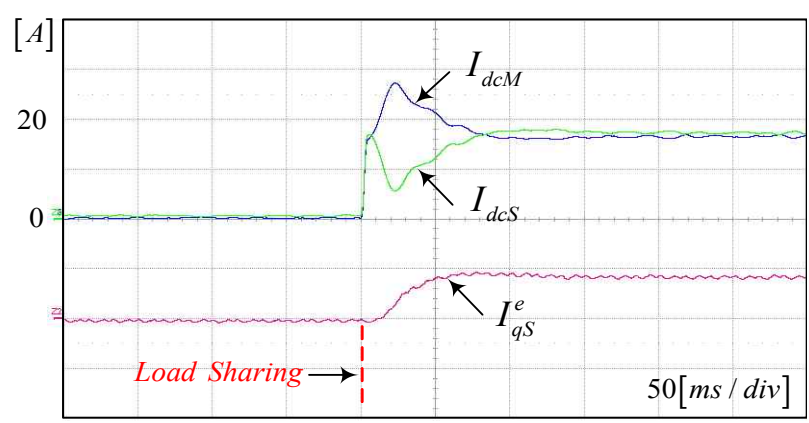

(a) $f(x)=\left[A x^{3}+(1-A) x\right], A=0.2$

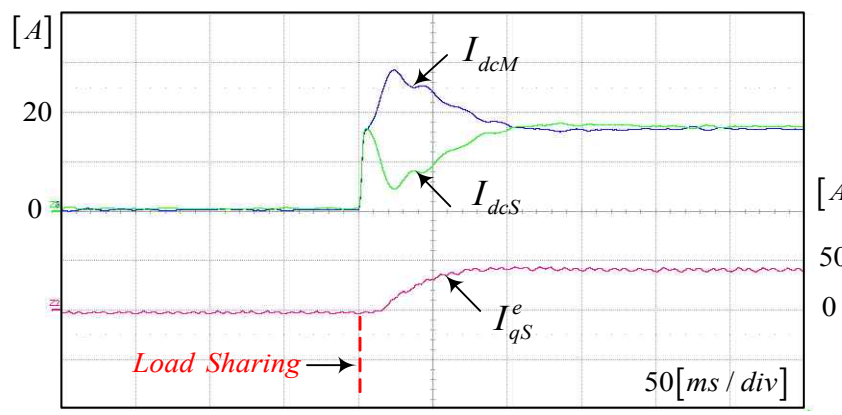

(b) $f(x)=\left[A x^{3}+(1-A) x\right], A=0.5$

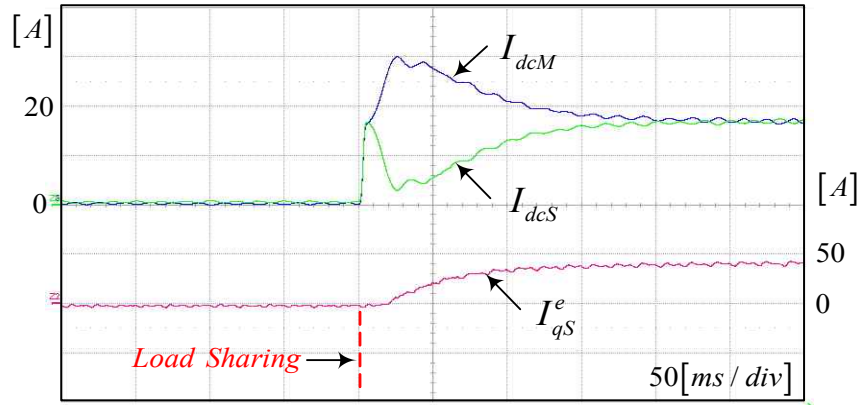

(c) $f(x)=\left[A x^{3}+(1-A) x\right], A=0.8$

Fig. 12 Output current waveform of each converter and Q-axis current of slave converter according to the change of A in Droop control

그림 12 는 3 차방정식의 $A$ 계수를 $0.2 \rightarrow 0.5 \rightarrow 0.8$ 로 변경하고 Droop 제어를 수행하였을 경우에 각 컨버터의 출력전류 파형과 slave 컨버터의 $q$ 축 전류 파형을 보여 준다. $A$ 의 값이 증가할수록 그림 5 의 그래프와 같이 slave 컨버터의 전류 변화가 완만하게 동작함을 확인 할 수 있다.

\section{6. 결 론}

직류배전을 위한 3상 $\mathrm{AC} / \mathrm{DC} \mathrm{PWM}$ 컨버터는 전력용 반도체의 용량 한계로 인하여 단일 시스템의 용량은 제 한적이며, 시스템 용량 증가를 위하여 $\mathrm{AC} / \mathrm{DC}$ 컨버터의 병렬운전이 필요하다. 제안한 방식은 master 시스템은 3 상전류를 동기좌표변환하고, 유효축인 $q$ 축 전류를 이용 하여 직류전압을 제어한다. slave 시스템은 master 시스 템의 직류출력 전류를 측정하고 이를 slave 시스템의 출
력전류와 오차를 계산함으로써 slave 시스템이 분담하여 야 할 전류를 계산한다. 이를 제안한 3차방정식을 이용 하여 slave 시스템의 $q$ 축 전류로 이용함으로써, 시뮬레 이션과 실험 결과와 같이 병렬시스템 간 순환전류 없이 부하를 분담함을 확인할 수 있다. 직류전류의 크기가 큰 경우는 방정식을 이용하여 빠르게 slave 모듈의 전류를 증가시키고, 전류의 오차가 작은 경우는 slave 모듈의 $q$ 축 전류를 더욱 작게 제어함으로써, 용량이 같은 두 시 스템에서 제어진동을 최소화하고 안정적으로 부하를 분 담할 수 있도록 하였다. 결과적으로 제안한 이론을 시뮬 레이션과 실험을 통하여 그 타당성을 검증하였다.

"이 논문은 2014년도 정부(미래창조과학부)의 재 원으로 한국연구재단의 지원을 받아 수행된 기초 연구사업임(No. 2011-0015584)"

\section{References}

[1] T. F. Wu, C. H. Chang, L. C. Lin, G. R. Yu, Y. R. Chang, "DC-Bus Voltage control With a Three-Phase Bidirectional Inverter for DC Distribution Systems," IEEE Transactions on Power Electronics, Vol. 28, No. 4, pp. 1890-1899, Apr. 2013.

[2] J. W. Kim, H. S. Choi, B. H. Cho, "A novel droop method for converter parallel operation," IEEE Transactions on Power Electronics, Vol. 17, No. 1, pp. 25-32, Jan. 2002.

[3] H. Kakigano, Y. Miura and T. Ise, "Low-voltage Bipolar-Type DC Microgrid for Super High Quality Distribution," IEEE Transactions on Power Electronics, Vol. 25, No. 12, pp. 3066-3075, Dec. 2010.

[4] H. Bevrani, S. Shokoohi, "An Intelligent Droop control for Simultaneous Voltage and Frequency Regulation in Islanded Microgrids," IEEE Transactions on Smart Grid, Vol. 4, No. 3, pp. 1505-1513, Sept. 2013.

[5] N. Pogaku, M. Prodanovic and T. C. Green, "Modeling, Analysis and Testing of Autonomous Operation of an Inverter-Based Microgrid," IEEE Transactions on Power Electronics, Vol. 22, No. 2, pp. 613-625, Mar. 2007.

[6] L. Xiong, W. Peng and C. L. Poh, "A Hybrid AC/DC Microgrid and Its Coordination Control," IEEE Transactions on Smart Grid, Vol. 2, No. 2, pp. 278-286, Jun. 2011.

[7] Y. A. Mohamed, E. F. EI-Saadany, "Adaptive Decentralized Droop Controller to Preserve Power sharing Stability of Paralleled Inverters in Distributed Generation Microgrids," IEEE Transactions on Power Electronics, Vol. 23, No. 6, pp. 2806-2816, Nov. 2008.

[8] B. Byeon, T. Yoon, S. Oh and G. Jang, "Energy 
Management Strategy of the DC Distribution System in Buildings using the EV Service Model," IEEE Transactions on Power Electronics, Vol. 28, No. 4, pp. 1544-1554, Apr. 2013.

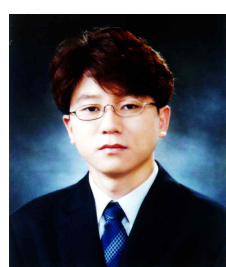

\section{신수철 (申守澈)}

1977년 2월 27일생. 2004년 수원대 전기전 자공학부 졸업. 2006년 성균관대 대학원 에 너지시스템공학과 졸업(석사). 2014년 성균 관대 대학원 전자전기컴퓨터공학과 졸업(공 박) 2006년 2010년 (주효성중공업 연구소 선임연구원. 2014년 현재 LG전자 VC연구소 전력전자연구파트 선임연구원.

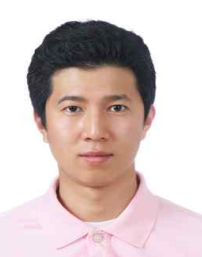

\section{이희 준(李羲俊)}

1982년 9월 30일생. 2008년 순천향대 졸업. 2011년 성균관대 대학원 메카트로닉스 협동 과정 졸업(석사). 2011년 현재 동 대학원 전자전기컴퓨터공학과 박사과정.

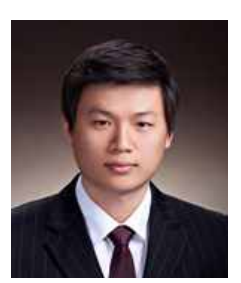

\section{박윤욱(朴潤郁)}

1985년 8월 20일생. 2008년 충남대 전자공 학교육과 졸업. 2012 현재 성균관대 대학 원 전자전기컴퓨터공학과 석사과정.

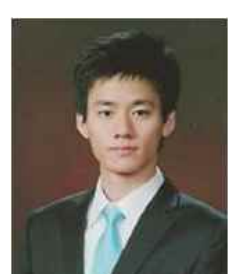

\section{홍석 진 (洪錫進)}

1985년 11월 11일생. 2012년 동양미래대 자 동화공학부 졸업. 2014년 성균관대 대학원 메카트로닉스공학협동과정 졸업(석사). 2014 년 현재 성균관대 태양광시스템공학 협동과 정 박사과정.

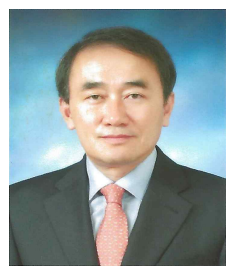

\section{원 충연 (元忠淵)}

1955년 5월 10일생. 1978년 성균관대 공대 전기공학과 졸업. 1980년 서울대 공대 대학 원 전기공학과 졸업(석사). 1987년 서울대 공대 대학원 전기공학과 졸업(공박). 1991년 12월 1992년 12월 미국 테네시 주립대학 전기공학과 방문 교수. 1998년 현재 한국철도기술연구원 심사 위원. 2006년 2009년 한국전력공사 PQ 심사위원. 2006년 2009년 차세대 첨단도시철도시스템(한국건설교통기술 평가원) 기술개발사업 운영위원. 2006년 현재 (주로템 기술자문위원. 2010년 2012년 도시철도 공사 기술검증위원. 2007년 현재 삼 성전기 에너지파워 연구센터장. 2011년 2013년 직류표준화 연 구회 회장. 2010년 당 학회 회장. 현재 성균관대 정보통신대학 교수. 